\section{Metacontrast: Further evidence for monotonic functions*}

\author{
LESTER A. LEFTON \\ University of Rochester, Rochester, N.Y. 14627
}

In three separate experiments three variables were examined which could be responsible for nonmonotonic metacontrast functions. Using letters as stimuli, monotonic functions were obtained for all three. Whatever the variables are, spatial uncertainty, retinal location, or spatial cueing do not seem to be involved in producing nonmonotonic functions.

Metacontrast studies have shown two types of results: functions that have been monotonic and those that have been nonmonotonic or $\mathrm{U}_{\text {-shaped. Because of the }}$ important theoretical implications of the shape of the metacontrast function, much attention has been devoted to the study of metacontrast.

A U-shaped function is one in which the maximum disruption occurs at a time greater than $t=0$, where $t=0$ is the offset of the stimulus. Evidence for U-shaped functions comes from a variety of studies: Alpern (1953) found U-shaped functions for brightness matching; Kolers \& Rosner (1960) found U-shaped functions with a disk and ring; and Weisstein \& Haber (1965) also found $U$-shaped functions with letters as stimuli and a ring. A partial replication of the Weisstein and Haber study was done by Mayzner et al (1965); other variations of the basic design were made by Weisstein (1966), both with essentially the same results. More recently, Weisstein, Jurkens, \& Onderisin (1970), comparing different types of response indicators, found further evidence for U-shaped functions.

There is support for monotonic metacontrast functions: Eriksen \& Collins (1964, 1965) found monotonic metacontrast functions using letters as stimuli and a ring. Eriksen, Becker, \& Hoffman (1970) tried to replicate the Weisstein \& Haber (1965) study precisely; however, they were unable to replicate U-shaped curves. With some basic improvements in the design, they found better identification of the stimuli with increases in the delay of the ring. In an attempt to replicate a study by Kolers (1962) where U-shaped functions were found, Eriksen \& Marshall (1969) found monotonic functions.

* This research was supported by a grant from the Lnited States Public Health Service. IIH 10753, to Dr. R. Y. Haber. The author wishes to thank Dr. A. O. Dick for his helpful comments and suggestions.

- Present Address: Department of Psychology, L'niversity of Rochester. Rochester. N. Y. 14627
Stewart \& Purcell (1970) have criticized Weisstein \& Haber (1965) on methodological grounds. They argued that Weisstein and Haber did not run a full factorial study and that they summed across retinal positions to obtain the function reported. They found, in a similar study, the functions to be $\mathrm{U}$-shaped when the stimuli were either $.60 \mathrm{deg}$ or $1.72 \mathrm{deg}$ from fixation: however, when the stimulus was located foveally, they found close to $100 \%$ accuracy across all delays of the ring. They argue, as does Alpern (1953), that retinal position is a crucial variable in studies of metacontrast.

Stewart \& Purcell (1970) presented the target and ring centrally and varied fixation, left or right. Since fixation in a study of the effects of retinal position is crucial, and a technique that does not motivate Ss to fixate, because they are aware of the location of the target, might not yield accurate results, Experiments 1 and 2 were undertaken to examine the effects of retinal position with central fixation and spatial uncertainty. In Experiment 2 the effects of spatial cueing were examined. In Experiment 3 the spatial uncertainty variable was eliminated, and the stimulus was always presented centrally.

\section{GENERAL METHOD}

Subjects

Graduate students at the University of Rochester served as paid volunteer Ss. There were seven, eight, and six $\mathrm{Ss}$ in Experiments 1,2, and 3, respectively; four Ss participated in all three experiments.

Stimuli and Apparatus

The stimuli were capital letters, $O$ and D. At a distance of 44 in. both subtended a visual angle of $.28 \mathrm{deg}$ vertically. The $\mathrm{O}$ subtended $.28 \mathrm{deg}$ horizontally, the D. .24 deg. The stroke width of the letters was $.08 \mathrm{deg}$. They were black Lettraset letters No. 108, Futura Bold, $20 \mathrm{pt} / \mathrm{d}$.

The masking ring was a Decadry transfer letter O, No.2736-C, $36 \mathrm{pt}$. The stroke width of the ring was $.08 \mathrm{deg}$. The ring subtended .50 deg vertically and horizontally. The angular separation between the stimulus letter $\mathrm{O}$ and the inner diameter of the masking ring was $.06 \mathrm{deg}$ vertically and .02 deg horizontally.

$$
\text { Procedure }
$$

After $5 \mathrm{~min}$ of adaptation to the ambient room illumination, each $\mathrm{S}$ was run in a forced-choice design. The stimuli were presented in a three-field tachistoscope (Scientific Prototype, Model GA). The duration of the stimulus, ring, and interstimulus interval were controlled by a PDP.8 computer. $\mathrm{S}$ initiated a trial by pressing a switch. After a 500 -msec delay, the stimulus appeared in Field 1 for $20 \mathrm{msec}$, the ring appeared in Field 2 for $50 \mathrm{msec}$. The fixation field was also between Fields 1 and 2 for 0, 30, or $90 \mathrm{msec}$. All fields were equated for an overall luminance at $8 \mathrm{fc}$.

Experiment 1

The stimulus occurred in one of five positions: centered just above the foveal fixation point, .60 or $1.72 \mathrm{deg}$ left or right of fixation. The five positions were carefully aligned so that they would fall just within the ring. The order of conditions was randomized; stimuli and rings were changed on each trial. After 20 practice trials, eight measurements were made per $S$ per experimental condition. Experiment 2

The stimuli were the same as in Experiment 1; the ring differed, however. Five rings appeared in Field 2; the rings were arranged side by side and aligned so that each ring would overlay one of the five retinal positions being studied. The order of conditions was randomized, and

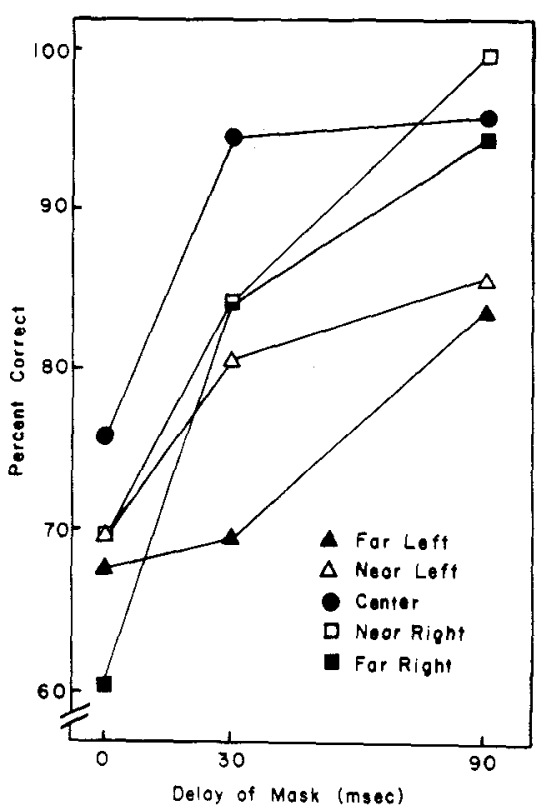

Fig. 1. The percentage of letters reported correctly for each of five retinal positions is plotted as a function of the delay of the masking ring. 


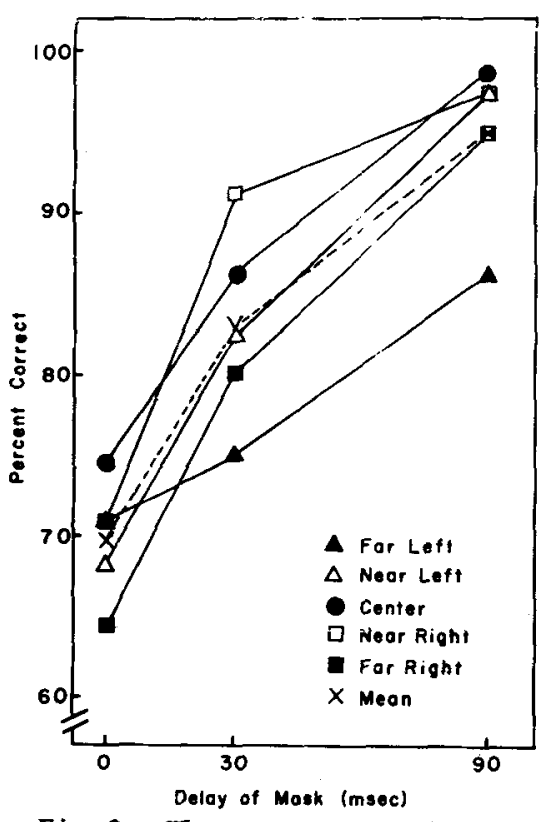

Fig. 2. The percentage of letters reported correctly for each of five retinal positions is plotted as a function of the delay of the five masking rings.

after 20 practice trials, eight measurements were made per $\mathrm{S}$ per condition.

\section{Experiment 3}

The stimulus and a ring were always presented just above the foveal fixation point. The trials were run in three blocks of 16 measurements; the order of the three blocks was counterbalanced between Ss.

\section{RESULTS}

\section{Experiment 1}

The number of errors made per condition was entered into an analysis of variance. The main effect of retinal position was significant $[F(4,24)=4.64$, $\mathbf{p}=.007]$. The main effect of delay was also highly significant $[\mathrm{F}(2,12)=29.01$, $p=.001]$. The interaction of delay and position failed to reach significance $(p=.149)$. Figure 1 presents the percentage of letters reported correctly for each of the five retinal positions examined as a function of the delay of the ring. All five functions are of positive slope and are monotonic. In general, the positions at the left were reported less accurately than the other positions; the central position was reported most accurately. The five curves do not order themselves in any systematic manner.

\section{Experiment 2}

The number of errors made per condition was entered into an analysis of variance. The main effect of delay was highly significant $[F(2,14)=31.85$, $\mathrm{p}<.001)$. The main effect of retinal position, however, did not reach significance $(p=.124)$, nor did the interaction of delay and position $(p=.878)$. The curves obtained for each retinal position are plotted as a function of the delay of the ring in Fig. 2. All of the curves are of positive slope and are monotonic. The functions exhibit no systematic order and do not differ statistically. Thus, the use of five rings eliminated any differences of retinal position.

\section{Experiment 3}

The number of errors made per condition was entered into an analysis of variance. The main effect of delay was highly significant $[F(2,10)=34.2$, $\mathrm{p}<.005]$. Figure 3 presents these results; the percentage of letters reported correctly as a function of the delay of the ring exhibits a function of positive slope and monotonicity. When spatial uncertainty is eliminated, monotonic functions are still obtained.

\section{DISCUSSION}

Three variables that could possibly contribute or be responsible for U-shaped functions were examined. Whatever the variables, they do not seem to be spatial uncertainty, retinal location, or spatial cueing. Experiment 1 found significant differences in retinal location; it was considered that a masking ring in a situation with spatial uncertainty can act as a cue, particularly at the shorter intervals. When a mask of five circles was used to eliminate the possibility of spatial cueing, analysis showed no differences in the retinal locations studied. All functions obtained were of positive slope and monotonic. Stewart \& Purcell (1970) found a flat function with accuracy close to $100 \%$ in the foveal position and $\mathrm{U}$-shaped functions in the other positions. Considering retinal anatomy, it seems somewhat unreasonable to expect masking functions to differ greatly within $.60 \mathrm{deg}$ of fixation. Two factors may have affected their results: (1) They used central presentation of the stimulus and varied fixation left and right, and (2) although they used trained psychophysical observers, shifts in S's strategy may have resulted from the use of a block design in varying fixation.

U.shaped functions may have been lost in the present study due to spatial uncertainty and problems in localization. A stimulus of $.28 \mathrm{deg} 1.72 \mathrm{deg}$ from fixation is difficult to localize and identify. Studies that have reported $U$-shaped functions have used larger stimuli; at the same distance from fixation, a larger stimulus will be more easily localized and identified than a smaller one. Experiment 3 eliminated the variable of spatial uncertainty; the function remained monotonic.

The present study presents no evidence for U-shaped metacontrast functions; whatever the underlying mechanisms, the

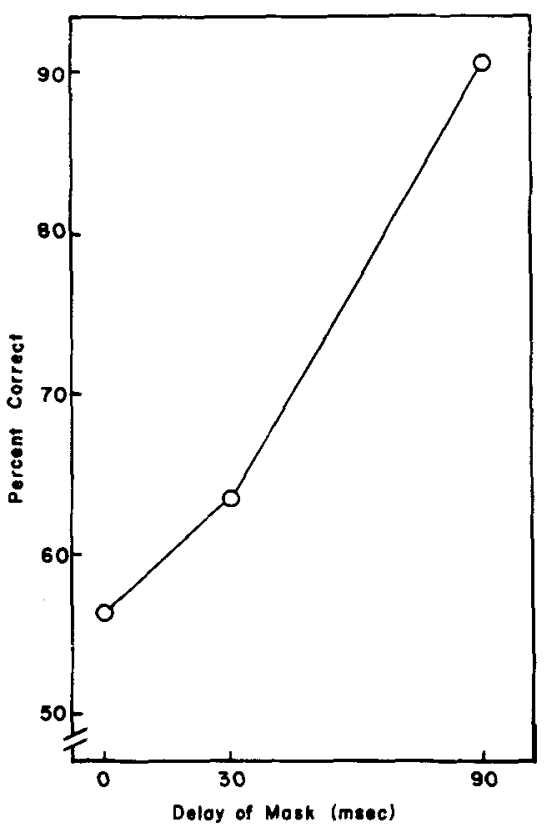

Fig. 3. The percentage of letters reported correctly is plotted as a function of the delay of the masking ring.

three variables considered did not affect the monotonic functions obtained.

\section{REFERENCES}

ALPERN, M. Metacontrast. Journal of the Optical Society of America, 1953, 43, 648-657.

ERIKSEN, C. W., BECKER, B. B., \& HOFFMAN, J. E. Safari to masking land: A hunt for the elusive U. Perception \& Psychophysics, 1970, 8, 245-250.

ERIKSEN, C. W., \& COLLINS, J. F. Backward masking in vision. Psychonomic Science, 1964, 1, 101-102.

ERIKSEN, C. W., \& COLLINS, J. F. Reinterpretation of one form of backward and forward masking in visual perception. Joumal of Experimental Psychology, 1965, 70, 343-351.

ERIKSEN, C. W., \& MARSHALL, P. H. Failure to replicate a reported U-shaped visual masking function. Psychonomic Science, 1969, 15, 195-196.

KOLERS, P. A. Intensity and contour effects in visual masking. Vision Research, 1962, 2, 277-294.

KOLERS, P. A., \& ROSNER, V. S. On visual masking (metacontrast): Dichoptic observation. American Journal of Psychology, $1960,73,2-21$.

MAYZNER, M. S., BLATT, M. H., BUCHSBAUM, W. H., FRIEDEL, R. T., GOODWIN, P. E., KANON, D., KELEMAN, A., \& NILSSON, W. D. A $u$-shaped backward masking function in vision: A partial replication of the Weisstein and Haber study with two ring sizes. Psychonomic Science, $1965,3,79-80$.

STEWART, A. L., \& PURCELL, D. G. U-shaped masking functions in visual backward masking: Effects of target configuration and retinal position. Perception \& Psychophysics, 1970, 7, 253-256.

WEISSTEIN, N. Backward masking and models of perceptual processing. Journal of Experimental Psychology, 1966, 72, 232-240. WEISSTEIN, N., \& HABER, R. N. A U-shaped 
backward masking function in vision. Psychonomic Science, 1965, 2, 75-76.

WEISSTEIN, N., JURKENS, $r$., \& ONDERISIN,

T. Effect of forced choice vis magnitude-estimation measures on the waveforms of metacontrast functions. Journal of the Optical Society of America, 1970, 60, 978-981.

\section{Interval estimation as a function of constant and interrupted stimulation*}

\author{
GERALD LONG and SUCHOON MO \\ The University of Detroit, Detroit, Mich. 48221
}

The present study investigated the relationship between a temporal interval's perceived length and the amount of stimulus and stimulus change within that interval. In three separate tests, completely filled intervals were found to be significantly overestimated by the $\mathrm{Ss}$ in comparison with empty intervals. In contrast to this, interrupted or divided intervals were underestimated.

There appears to be some confusion over the effects of stimulation upon short temporal estimations. It is generally agreed that, in comparison with an "empty" interval, a completely "filled" temporal interval (i.e., some stimulus duration) is usually overestimated by S (Meumann, 1896; Fraisse, 1963). However, the effects of "interrupting" or "dividing" temporal intervals are still somewhat in question. Following Hall \& Jastrow (1886), Fraisse (1961, 1963, 1965) has attempted to draw an analogy between Uppel's illusion of visual extent, in which a divided line appears longer than an unbroken line, and the interrupting of a

*The authors wish to thank Mr. Jerome Heckenmueller and Mr. Robert Novelly for their aid in analyzing the data and Miss Cathy McIvor for her help in its collection. temporal interval with various stimuli. Such an interrupted or broken interval should then appear longer or be overestimated by $\mathrm{S}$ when compared to an empty interval of objectively the same length. Other researchers, however, have found opposite results in their studies, results perhaps more in line with the common-sense notion of change making time appear to pass more quickly (Benussi, 1917; Roelofs \& Zeeman, 1949, 1951; Hawkins \& Meyer, 1965). The present study attempts to clarify this area in regard to the effects of both constant and interrupted stimulation upon $\mathrm{S}$ 's short temporal estimations.

\section{METHOD}

The Ss were 13 male and 12 female undergraduates at the University of Detroit. The apparatus employed were a Lafayette reaction-time machine, an
Industrial Timer Corporation stopclock, a buzzer, and a telegraph key. By depressing a button, E could both start the timer and present a light of moderate intensity to $\mathrm{S}$. $S$ had before him a button which, by depressing, would terminate the light stimulus and stop the timer. $E$ also controlled a buzzer by means of a telegraph key, thereby enabling him to present the buzzing sound at any point during any of the trials. Finally, all trials were run in a semidark and sound-deadened room.

Test 1

Each of 15 Ss was initially run through 10 practice trials in which $\mathrm{E}$ presented the light and, after $3.25 \mathrm{sec}$, instructed $S$ to terminate it by pressing his button. This was done to acquaint $S$ with the approximate length of a $3.25-\mathrm{sec}$ interval. Forty test trials now followed in which $S$ was instructed to "pay attention" to the light before him. When it went on, he was to estimate $3.25 \mathrm{sec}$ and then turn it off by pressing the button. There was approximately a 5-sec intertrial interval. Randomly mixed within the 40 trials were four different auditory conditions (10 trials of each), which differed as to the amount of buzzer presented by $E$ during the interval. On any particular trial, $E$ presented the buzzer once (B1) or twice (B2) or continuously (BC) or not at all (NB). S's temporal productions of his estimate of a 3.25 -sec light duration were recorded by $E$ from the stopclock after each trial. $\mathrm{S}$ was instructed to sit quite still and not to use any form of rhythmical tapping in estimating the duration.

Test 2

The instructions given $S$ and the procedure followed in Test 2 were almost identical with those of Test 1 , except that the length of the light duration to be

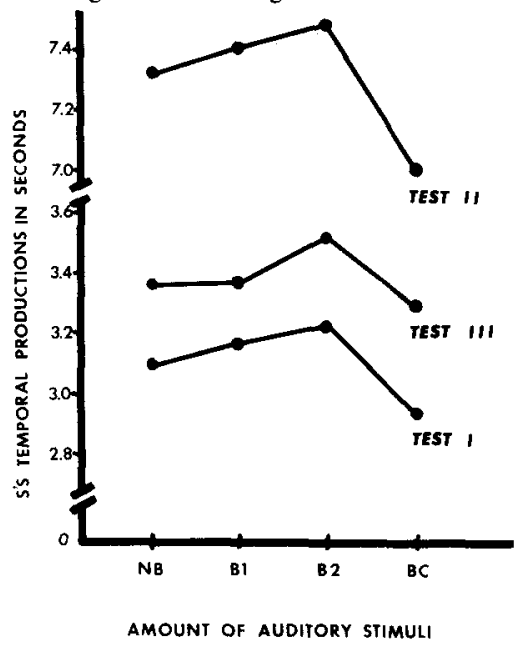

Fig. 1. The effects of varying amounts of auditory stimuli upon S's temporal estimations. 